\title{
Osteocalcin Improved Spermatogenesis in Azoospermic Mouse Model
}

\section{OPEN ACCESS}

Citation: Shafaat P., Mougahi S.M.H.N., Parvari S., Solhjo S., Tooli H., Nejad M.Y., Dhulqarnain A.O., Rastegar T (2018) Osteocalcin Improved Spermatogenesis in Azoospermic Mouse Model.Open Science Journal 3(1)

Received: $4^{\text {th }}$ February 2018

Accepted: $17^{\text {th }}$ February 2018

Published: $4^{\text {th }}$ March 2018

Copyright:@ 2018 This is an open access article under the terms of the Creative Commons

Attribution License, which permits unrestricted use, distribution, and reproduction in any medium, provided the original author and source are credited.

Funding: This work supported by grant No.29275 from Tehran University of Medical Sciences

Competing Interests: The author have declared that no competing interests exists.

\author{
Pedram Shafaat ${ }^{1}$, Seyed Mohammad Hosein Noori Mougahi ${ }^{1}$, \\ Soraya Parvari ${ }^{2}$, Somayeh Solhjo ${ }^{1}$, Heidar Tooli ${ }^{1}$, Mahsa Yaahoobi \\ Nejad $^{1}$, Akanji Omotosho Dhulqarnain ${ }^{1}$, Tayebeh Rastegar ${ }^{1 *}$ \\ ${ }^{1}$ Tehran University of Medical Science, Tehran, Iran \\ ${ }^{2}$ Alborz University of Medical Science, Karaj, Iran \\ *Corresponding author: Tayebeh Rastegar: trastegar@tums.ac.ir
}

\section{Abstract:}

Infertility is one of the major health concerns in the world whose globally incidence rate is on the rise. Several hormones are effective in this process, such as testosterone, estrogen and Osteocalcin (OCN). The Osteocalcin has Gprc6a receptors on leydig cells, which promotes the production of testosterone when mounted on these receptors. Therefore, the aim of this study was to investigate the role of Osteocalcin on the improvement of spermatogenesis and expression of Gprc6a receptors on leydig cells in the azoospermic mouse model.

Twenty-five mice ( 4 to 6 weeks) were randomly divided into five groups: control, sham I Group that was initially injected by busulfan solvent (DMSO) at 5 week old and then by Osteocalcin solvent (PBS) after 5 weeks for one months, azoospermia Group that received busulfan ( $40 \mathrm{mg} / \mathrm{kg} / \mathrm{ip}$ ) at 5 week old. Sham II Group received busulfan $40 \mathrm{mg} / \mathrm{kg} / \mathrm{ip}$ and then after 5 weeks received PBS and experimental group, including azoospermic mice, was administered by Osteocalcin $(3 \mathrm{ng} / \mathrm{g} / \mathrm{d})$ for one month. After the last injection, the testes were dissected and then exposed to the tissue passage. To measure morphological changes, $\mathrm{H} \& \mathrm{E}$ staining was performed on a number of sections to measure the diameter of the seminiferous tubule, thickness of the germinal layer, count the spermatogonial cells, spermatocyte, round spermatid, long spermatid, Sertoli, leydig and myoid cells. Image J software was used to conduct quantitative studies. Immunohistochemical method was employed to examine the expression of specific receptor of Osteocalcin, Gprc6 $\alpha$, in the Leydig cell among the groups. 
The $\mathrm{H} \&$ E staining showed a significant difference in the count the spermatogonial cells, spermatocytes, round spermatids, long spermatids, thickness of the germ layer, the seminiferous tubule diameter between the studied groups $(\mathrm{P}<0.05)$.

There was also no significant difference in the count of Sertoli, leydig, myoid cells and seminiferous tubule diameter between the groups $(\mathrm{P}<0.05)$. In the immune histochemistry, no significant difference was found in the count of GpRC6 $\alpha$-positive leydig cells between the groups $(\mathrm{P}<0.05)$.

According to the current results, the OCN plays an important role in spermatogenesis, which has a positive effect on the count of spermatocytes and spermatids, and can be further explored as an appropriate therapeutic strategy proposed for the infertility.

Keywords: Osteocalcin, Spermatogenesis, Azoospermia, Leydig Cell, Gprc6 $\alpha$

\section{Introduction}

Infertility is one of the major health concerns in the world whose globally incidence rate is on the rise (1). Different global statistics equate the roles of women and men in the infertility and the male factor is responsible for almost half of the infertility(2).

The main function of the testes is the synthesis of sex hormones and the production of spermatozoa (3). It has been revealed that many hormones affect the fertility process, most notably testosterone and estrogen(4). Osteocalcin $(\mathrm{OCN})$ is another hormone that is known to influence the spermatogenesis. The Osteocalcin is released by osteoblasts and effected in male fertility in transgenic mouse models by increasing testosterone production and sperm count(5). The Osteocalcin directly controls the formation of testosterone by the leydig cells in the testes by its receptor (Gprc6 $\alpha$ ) (6). The function of androgen receptors is essential for the sexual differentiation in the male embryo, the development in puberty, reproduction and differentiation of the germ cells, the support of germ cells and the regulation of the spermatogenesis process in mammals(7). Chemotherapy and radiotherapy preferably disrupt the function of dividing cells, including spermatogonium and spermatocyte in the testicles. These treatments have significant effects on the spermatogenesis. (8). Lee et al. (2011) stated that the bone might play a role in controlling male fertility, with an emphasis on the direct role of Osteocalcin in testosterone production in leydig cells(4). The authors compared OCN knocked out mice or ESP knocked out mice with the control group to support this data, in vivo. They observed that the testes weight, the sperm count and the circulating testosterone level had been decreased dramatically in the OCN knocked out mice and were increased in the ESP knocked out male mice. In addition, they reported that the deletion of Gprc6a led to the emergence of a testicular phenotype with a decrease in the 
testosterone level. Therefore, they stated that the Gprc6a dysexpression, induced mice with phenotype similar to the OCN knocked out mice(4). Oury et al. (2012) studied the interrelationship between bones and gonads, and stated that the skeletal system is an endocrine gland that promotes the synthesis of testosterone by the secretion of Osteocalcin hormone. The testosterone and the estrogen are important for maintaining the integrity of the skeleton bone mass in male and female during puberty $(9)$.

In this study we examined the effect of Osteocalcin on the promotion of spermatogenesis in the azoospermic mouse model, also we investigated expression of Gprc6a receptors on leydig cells as OCN receptor.

\section{Materials and Methods}

\section{Animal Preparation}

Male mice (NMRI) ranging in age from 4 to 6 weeks $(22 \pm 5 \mathrm{~g})$ were obtained from the Pasteur institute of Iran. Animals were housed in wire cages at $22 \pm 1^{\circ} \mathrm{C}$ under a $12 \mathrm{~h}$ light dark cycle with $70 \%$ humidity and fed a standard diet and water. Animals were maintained and experiments were conducted in accordance with the Principles of Laboratory Animal Care of Tehran University of Medical Sciences, Iran. The Animal Ethical Committees of the Tehran University of Medical Sciences approved the use of animals for the study.

All animals were randomly allocated into five groups, Control group $(n=5)$, Azoospermic experimental group $(n=5)$ that received a single intraperitoneal injection of busulfan (40 mg/ $\mathrm{kg}$ body weight) diluted in DMSO(dimethyl sulfoxide, USA) at 5 week old $(10)$, Sham I group $(n=5)$ that received a single intraperitoneal injection of DMSO (busulfan solvent) at 5 week old, Sham II $\operatorname{group}(\mathrm{n}=5)$ that received a single intraperitoneal injection of DMSO at 5 week old and after 5 weeks they received PBS(phosphate buffer solution) intraperitoneal injection $0.3 \mathrm{ml} / \mathrm{d}$ for 1 month and Azoospermic experimental treated group $(\mathrm{n}=5)$ that received a single intraperitoneal injection of busulfan (40 mg/kg body weight) diluted in DMSO at 5 week old and after 5 weeks they received Recombinant Osteocalcin (OCN)(H00000632, novus,USA) intraperitoneal injection $3 \mathrm{ng} / \mathrm{gr} / \mathrm{d}$ for 1 month(11).

\section{Drugs preparation}

Busulfan (B2635, Sigma, USA) was first dissolved in DMSO (P8340, Sigma, USA), then an equal volume of sterile water was added to obtain a final busulfan concentration of $20 \mathrm{mg} / \mathrm{ml}$. Osteocalcin dissolved in PBS (P4417, Sigma, USA) and then ten-week-old mice that previosely injected with busulfan (40 mg/kg body weight) on 5 week old were treated by i.p. injections with recombinant Osteocalcin (3 ng/g daily) for 1 month(12).

\section{Surgical procedure}


At the end of the treatment period, (15th week) the mice were weighed and anesthetized by using intraperitoneal ketamine $(50 \mathrm{mg} / \mathrm{kg}$ and xylezin $20 \mathrm{mg} / \mathrm{kg}$ ), blood depletion done from heart and then mice killed; the peritoneal cavity was opened through a lower transverse abdominal incision. Left testes in all groups were immediately removed, weighed and put in fixative for staining (13).

\section{Preparation of Busulfan-Induced Azoospermic Model}

The busulfan-treated infertile mouse model was prepared as described by Brinster with some modification. Mice were received a single dose intraperitoneal injection of busulfan (40 mg/kg, Sigma, St. Louis, MI, USA) at 4-6 weeks of age. Hematoxylin-Eosin stain of testicular cross section also eosin Nigrosine staining of seminal fluid was performed to evaluate the Azospermic model 5 weeks after busulfan injection $(10,14)$

\section{Confirmation of Busulfan-Induced Azoosperic Model}

\section{Hematoxylin and eosin $(H \& E)$ staining technique}

Hematoxylin and eosin (H\&E) stains have been used for at least a century and are still essential for recognizing various tissue types and the morphologic changes. Testes tissues of control and azoospemic mouse were fixed in buine's solution, embedded in paraffin, sectioned at $5 \mu \mathrm{m}$ and sections were stained with hematoxylin and eosin (H\&E), then morphological aspect of seminiferous tubules studied (15).

\section{The eosin-nigrosin staining technique}

Eosin-Nigrosin is a staining technique that assesses the vitality of a sperm sample. Briefly $20 \mu \mathrm{l}$ of semen were gently stirred $\left(30 \mathrm{~s}\right.$ at $\left.37{ }^{\circ} \mathrm{C}\right)$ in $60 \mu \mathrm{l}$ of eosin-nigrosin stain (5\%-nigrosin and 4\%-eosin-Y at ratio $3: 1$ ). Then, smears were prepared and dried at room temperature. The slides were examined by a single observer with phase-contrast microscope (magnification: X 1000) after preparation. A total of 200 spermatozoa per slide were scored for dead/live spermatozoa. This method is based on the degree of membrane permeability of dead spermatozoa which heads show pink or red coloration, whereas the low permeability of live gametes excludes eosin and therefore their head maintains whitish. Sperm that were stained, classified as dead, with sole exclusion for sperm with a light pink appearance to the neck region, which were described as live (14).

\section{Immunohistochemistry for Gprc6 $\alpha$}


Testes tissues were fixed in Formaldehyde solution, embedded in paraffin, sectioned at $5 \mu \mathrm{m}$, after antigen retrieval, endogenous peroxidase blocking, sections were incubated with primary polyclonal anti Gprc6 $\alpha$ (sc-67302, Santa Cruz, 1/100/overnight) and then secondary HRP conjugated antibody (ab6721,abcam,1/100/2h) was added. Counterstain nucleus staining was done by hematoxilin.

\section{Statistics}

The results were expressed as mean \pm SE. The statistical significance between the mean values was determined by one-way ANOVA analysis of variance, Tukey and Duncan post-test. $\mathrm{P} \leq 0.05$ was considered significant.

\section{Results}

\section{Osteocalcin increased testes weight of azoospermic mice}

Testis weight was reduced in azoospermic and sham II group compared to control and sham I groups, but in azoospermic OCN treated group is more than azoospermic mice (Fig. 1) $(\mathrm{p} \leq 0.05)$.

\section{testes weight}

mg

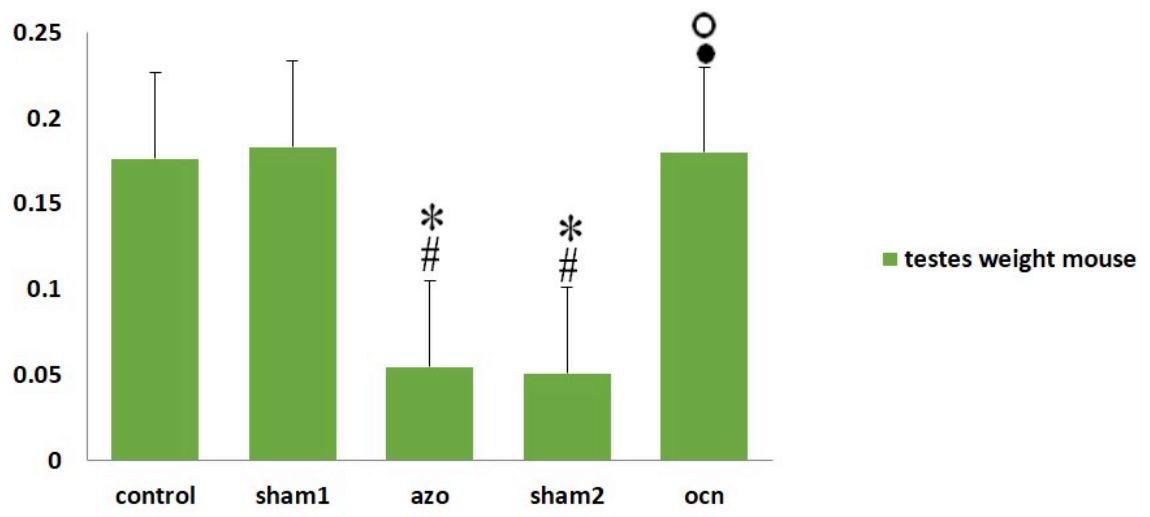

Figure 1- Testis weight in different groups. Testis weight was reduced in azoospermic and Sham II groups compared to control and Sham I group, but in azoospermic OCN treated group is more than azoospermicand Sham II mice $(\mathrm{p} \leq 0.05)$. \# significant with control group; * significant with Sham1 group; • significant with azoospermic group; ${ }^{\circ}$ significant with Sham II group. 


\section{Confirmation of the azoospermic model}

The results of the eosin-nigrosin staining technique for confirmation of the azoospermic model, which was investigated by the phase-contrast microscope, indicated penetration of acidic dye into the dead sperm head that is therefore visible in pink, while the live sperm head is colorless (Fig. 2 A, B). In addition, the results of Hematoxylin-Eosin staining for counting the seminiferous tubule examined by optical microscopy indicated that the tubules were relatively emptied and vacuolated in the azoospermia group in comparison to the control group, and the absence of the germ layer cells shows the destruction of spermatogenesis (Fig. 2 C, D).
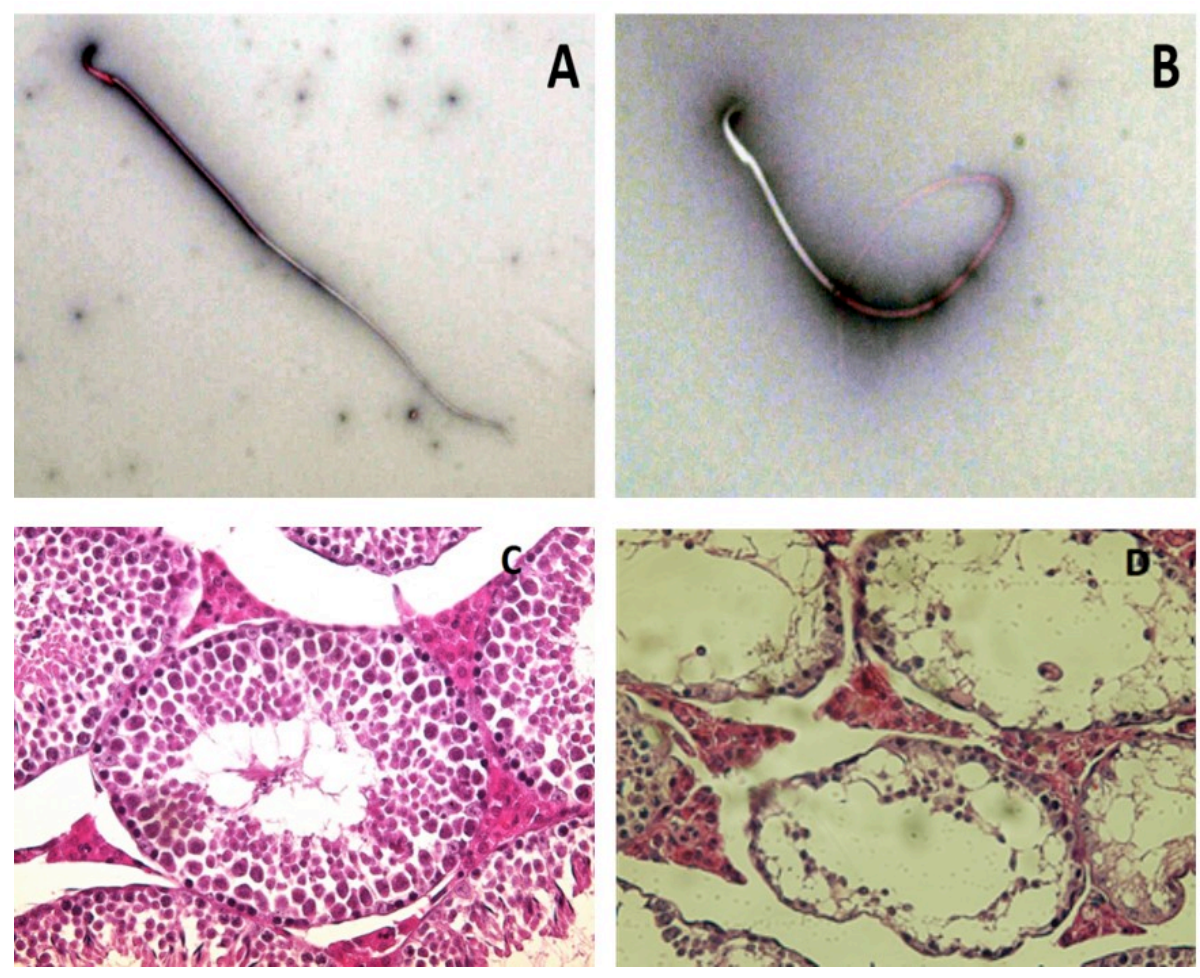

Figure 2: The Eosin-Nigrosin-stain produces a dark background on which the sperm stand out as lightly colored objects. (A) Dead sperm take up eosin and appear pinkish in color (B) whereas normal live sperm exclude the eosin stain and appear white in color. Busulfan induced azoospermic model preparation. C: Histological morphology of untreated testicle, as normal control; D: Histological morphology of testicular tissue 5 week after injection with $40 \mathrm{mg} / \mathrm{kg}$ busulfan. Most of the endogenous sperm cells had been removed, while interstitial tissue and Sertoli cells remained (bar: 50).

\section{Evaluation of the variables of the seminiferous tubule}

The results of hematoxylin-eosin staining for Morpholog analyzing of the seminiferous tubule are shown in figure 3. The control and sham I groups contain normal spermatogenesis and thick germ layer of the testicular tissue, 
but testicular tissue in the azoospermia and sham II groups, the tubules were relatively vacuolated. The absence of the germ layer cells shows the destruction of spermatogenesis. The testicular tubules in the Osteocalcin treated group, thick germ layer and the presence of various germ cells show the improvement and presence of spermatogenesis.

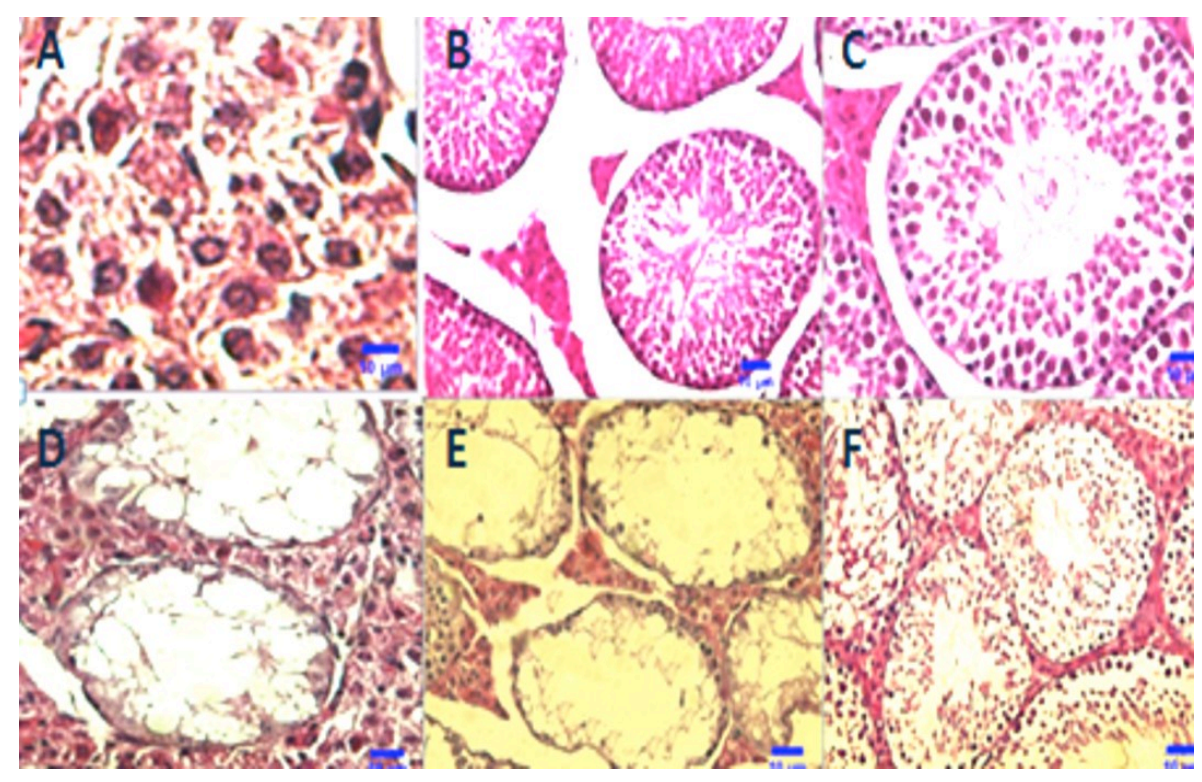

Figure 3- Hematoxylin-eosin staining: (A) Leydig cell (arrow) display in the testicular interstitial tissue; (B) Cross-section of the testicular tissue in the control group with normal spermatogenesis and thick germ layer; (C) Crosssection of testicular tissue in sham I group; (D) Cross-section of testicular tissue in the azoospermia group, the tubules were relatively vacuolated. The absence of the germ layer cells shows the destruction of spermatogenesis; (E) Crosssection of the testicular tissue in the sham II group, see the presence of vacuoles and absence of the germ layer cells; (F) Cross-section of the testicular tissue in the group treated with Osteocalcin, thick germ layer and the presence of various germ cells show the improvement and presence of spermatogenesis (bar: 100 in $\mathrm{A}$ and 50 in B, C, D, E, F).

Based on the one-way ANOVA and according to the Tukey's test there was a significant difference between the groups in the number of spermatogonial cells, spermatocytes, round spermatid and elongated spermatid and the thickness of the germinal layer of the seminiferous tubule $(\mathrm{P}<0.05)$. Also there was no significant difference in the number of Sertoli, leydig and myoid cells and diameter of the seminiferous tubule between the groups $(\mathrm{P}>0.05)$ (Fig.4). 

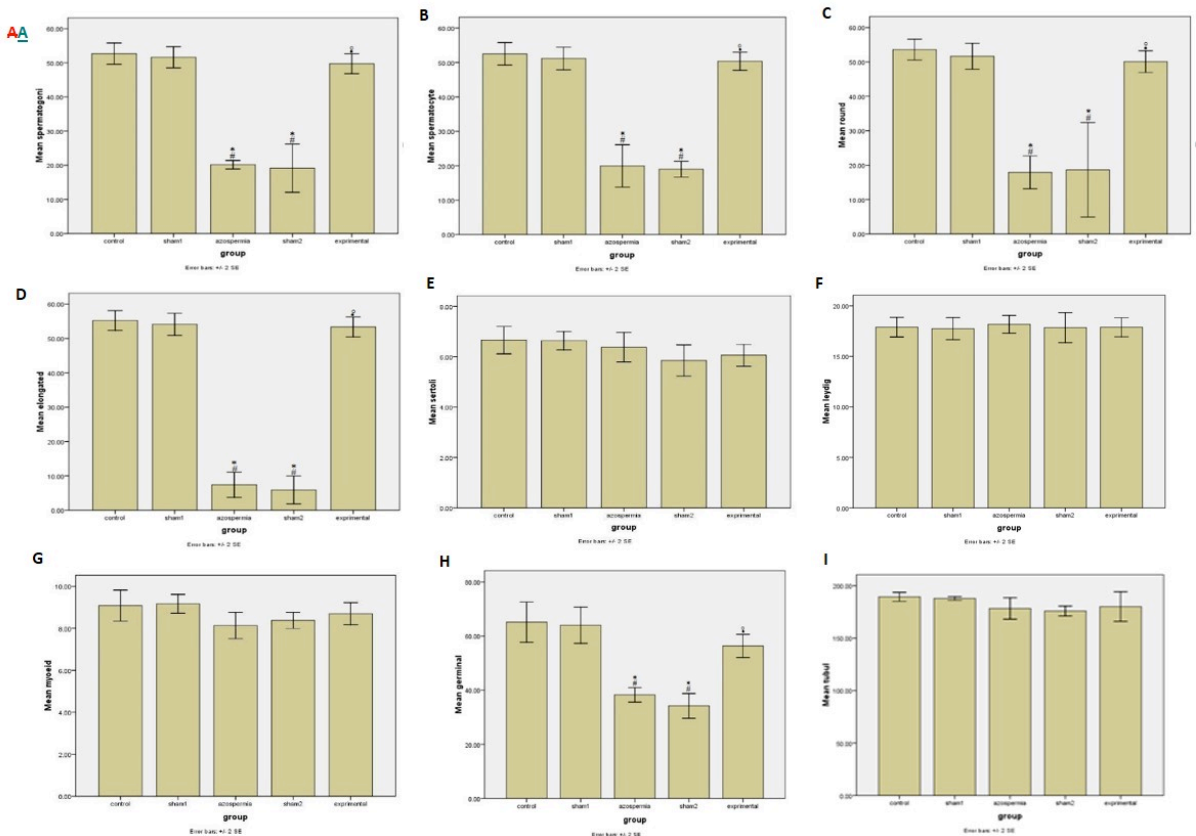

Figure 4: Data of the Variables of the testis Seminiferous Tubule. A: number of spermatogonia cells; B: Spermatocytes; C: Round spermatid cells; D: Elongated spermatid cells; E: Sertoli cells; F: Leydig cells; G: Myoid cells; H: Germinal layer thickness; I: Seminiferous tubules diameter $(\mathrm{P}<0.05)$. \# Significant with control group; * Significant with sham1 group; •Significant with Azoospermic group; ${ }^{\circ}$ Significant with sham2 group; Control: Control group; Sham I: which received solvents (DMSO and PBS); azospermia :

Azoospermiac animals that received busulfan $40 \mathrm{mg} / \mathrm{kg} / \mathrm{Ip}$; Sham-II:

Azoospermiac mice received PBS for 1month; Experimental: azoospermic mice that received Osteocalcin.

\section{Expression of Gprc6 $\alpha$}

The findings of immunohistochemical staining for the evaluation of GpRC6 $\alpha$ positive cells are presented in figure 5. The findings from the expression of the Osteocalcin receptor, GPRC6 $\alpha$, based on one-way ANOVA and Tukey's test indicated no significant difference in the count of GpRC6 $\alpha$-positive cells between the groups (Fig. 5) $(\mathrm{P} \leq 0.05)$. 


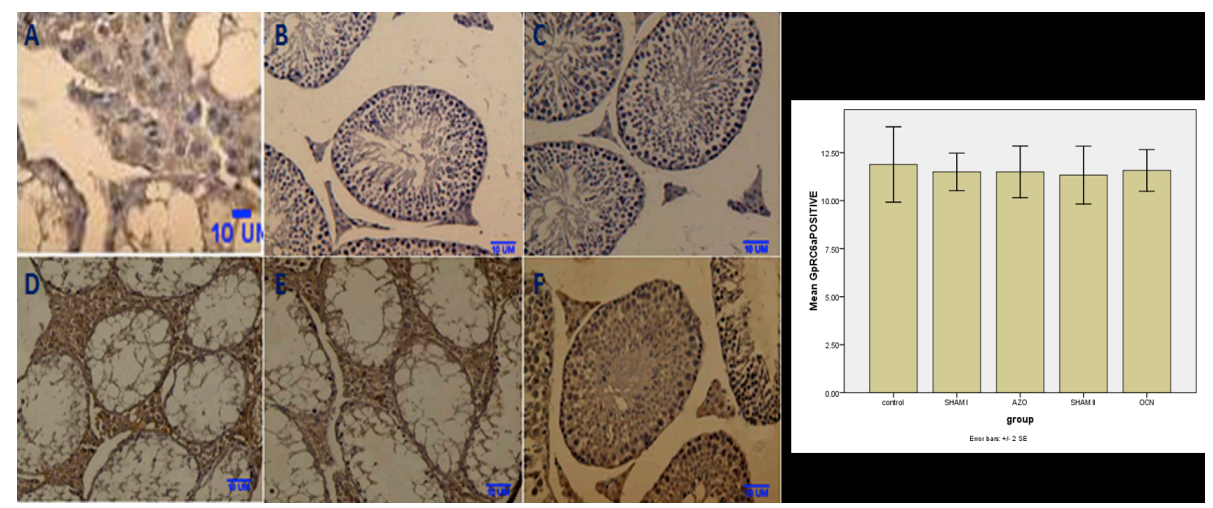

Figure 5- Immunohistochemical staining: (A) GpRC6 $\alpha$-positive leydig cell (arrow head) display in the testicular interstitial tissue; (B) Cross-section of the testicular tissue in the control group with normal spermatogenesis and thick germinal layer; (C) Cross-section of testicular tissue in sham I group; (D) Crosssection of testicular tissue in the azoospermia group, the tubules were relatively vacuolated and germinal layer cells were absent that shown the destruction of spermatogenesis; (E) Cross-section of the testicular tissue in the sham II group, the presence of vacuoles and tubules without any germinal cells; (F) Crosssection of the testicular tissue in the group treated with Osteocalcin, thick germinal layer and the presence of various germ cells show the improvement

and presence of spermatogenesis (bar: 40 in A and 25 in B, C, D, E, F).

Control: Control group; Sham I: which received solvents (DMSO and PBS); azospermia : Azoospermiac animals that received busulfan $40 \mathrm{mg} / \mathrm{kg} / \mathrm{Ip}$; Sham-

II: Azoospermiac mice received PBS for 1month; Experimental: azoospermic mice that received Osteocalcin. The number of GpRC6 $\alpha$-positive leydig cells, no significant difference was seen between the groups $(\mathrm{P} \leq 0.05)$.

\section{Discussion}

The experimental studies have proven that there are deficiencies in the Osteocalcin messaging pathway that are important in the male infertility.

In the present study, increasing the number of germ cells following the injection of Osteocalcin on the azoospermic mouse model confirmed that the Osteocalcin could play an important role in the spermatogenesis and fertility. Oury et al. were shown that osteocalcin is a bone-derived hormone favoring fertility in male mice by promoting Leydig cell maturation and testosterone production (6), Although in another study they shown that histological analysis of testes of 10 -week-old male mice injected with osteocalcin failed to show any improvement in spermatogenesis or a reversal of their Leydig cell (16). Also they confirmed that Osteocalcin-/- male mice are subfertile with a marked decrease in circulating testosterone and low sperm count (17).

$\mathrm{Pi}$ et al. for the first time suggested the role of GPRC6A in testicular function by creating GPRC6A $\mathrm{A}^{-/-}$mice. The GPRC6A is widely expressed in many tissues and organs, including the lung, liver, spleen, heart, kidneys, skeletal muscle, testicles, brain and bones. Although the metabolic function of 
several organs is affected by the malfunction of the GPRC6A gene in mice, but the most prominent feature is the incidence of woman lines in male GPRC6A $\mathrm{A}^{-/-}$ mice, which is associated with decreased testosterone levels and increased estrogen levels (18-20). These male mice were infertile that showed a decrease in the testosterone levels and the sperm count (17). In addition, the study of polymorphism in rs2274911 in the GPRC6A gene has been shown in several groups of patients as this polymorphism is associated with cryptorchidism in children and different phenotypes in adults (21). Oury et al. examined the patients with testicular dysfunction and observed that two of them were heterozygous for the mutation in the exon 4 of the GPRC6A gene, meaning that this mutation affects a highly conserved amino acid located in one of cross membrane regions of the molecule. This mutation prevents the integration of this protein in the cell membrane and thus causes the GPRC6A dysfunction. Cell-based evaluations have shown that this mutation also affects the negative dominant status in the cells. In fact, these observations indicate that the Osteocalcin deficiency and its receptor, GPRC6A, could play an important role in the phenotypic incidence of testicular dysfunction (16).

Recent studies confirmed that the pancreas-bone-testis axis has direct, bilateral and functional effects on each other as well as evolution through its discharge. In addition, the hypothalamic-pituitary-testicular axis operates predominantly against this axis, increases the exogenous levels of Osteocalcin, consequently enhances the level of testosterone and spermatogenesis, and then remains somewhat stable $(16,22)$.

Kirmani et al. found a direct relationship between total OCN and testosterone in boys aged between 11 and 14 years(23). On the other hand, Kanazawa et al. observed a strong association between ucOCN and serum testosterone levels in the males with type II diabetes (24). The results of Legrand et al. (2001) were contradictory to these observations. They evaluated 40 men and 80 women with osteoporosis and found no association between OCN and testosterone serum level (25). Another study on 614 men aged 65-88 years showed that the serum Osteocalcin had a negative correlation with free testosterone levels (26).

The difference between the results of the studies is probably due to the difference in the population studied in terms of age, model and other factors.

On the other hand, the results of the present study regarding the relationship between $\mathrm{OCN}$, and testis weight represent a strong relationship, inconsistent with the results of the Schwetz et al study. They found no strong association between OCN, testosterone levels, sperm concentration and spermatogenesis $(5,27)$. However Oury was observed that osteocalcin in transgenic mice increased testes, epididymides, and seminal vesicle weights, sperm count, and circulating testosterone levels (16). Osteocalcin has emerged as an important regulator of glucose and lipid metabolism, $\beta$ cell proliferation, glucose tolerance and insulin sensitivity. These mechanism and function of osteocalcin revealed that it indirectly could regulate spermatogenesis and fertility (12).

The mechanism of the effect of Osteocalcin on testosterone is still unknown in human beings, but is relatively clear in animal models. The Osteocalcin plays a role through the pancreas-bone-testis axis in line and independent of the hypothalamic-pituitary-testicular axis, promotes testosterone biosynthesis, and 
thus regulates reproductive performance and sperm production in men $(28,29)$, however our data confirmed the hypothalamic-pituitary-testicular axis is dominant in spermatogenesis and fertility.

\section{Conclusion}

According to the present results, the presence of OCN plays a major role in the functioning of the reproductive system and improves spermatogenesis in the azoospermic model, has a positive effect on the number of germ cells and expression of GPRC6a and can be further explored as an appropriate therapeutic strategy proposed for infertility.

\section{Acknowledgment}

This work supported by grant No.29275 from Tehran University of Medical Sciences.

\section{References:}

Zegers-Hochschild F, Adamson GD, de Mouzon J, Ishihara O, Mansour R, Nygren K, et al. The international committee for monitoring assisted reproductive technology (ICMART) and the world health organization (WHO) revised glossary on ART terminology, 2009. Human reproduction. 2009;24(11):2683-7.

Hodžić A, Ristanović M, Zorn B, Tulić C, Maver A, Novaković I, et al. Genetic variation in circadian rhythm genes CLOCK and ARNTL as risk factor for male infertility. PloS one. 2013;8(3):e59220.

Blomberg Jensen M. Vitamin D and male reproduction. Nat Rev Endocrinol. 2014;10(3):175-86.

Smith LB, Saunders PT. The skeleton: the new controller of male fertility? Cell. 2011;144(5):642-3.

Schwetz V, Gumpold R, Graupp M, Hacker N, Schweighofer N, Trummer O, et al. Osteocalcin is not a strong determinant of serum testosterone and sperm count in men from infertile couples. Andrology. 2013;1(4):590-4.

Oury F. A crosstalk between bone and gonads. Annals of the New York Academy of Sciences. 2012;1260(1):1-7.

Holdcraft RW, Braun RE. Androgen receptor function is required in Sertoli cells for the terminal differentiation of haploid spermatids. Development. 2004;131(2):459-67.

Yokonishi T, Ogawa T. Cryopreservation of testis tissues and in vitro spermatogenesis. Reproductive medicine and biology. 2016;15(1):21-8.

Khosla S, Riggs BL. Pathophysiology of age-related bone loss and osteoporosis. Endocrinology and Metabolism Clinics. 2005;34(4):1015-30.

Brinster CJ, Ryu B-Y, Avarbock MR, Karagenc L, Brinster RL, Orwig KE. Restoration of Fertility by Germ Cell Transplantation Requires Effective Recipient Preparation 1. Biology of reproduction. 2003;69(2):412-20.

Pi M, Wu Y, Quarles LD. GPRC6A mediates responses to osteocalcin in $\beta$-cells in vitro and pancreas in vivo. Journal of Bone and Mineral Research. 2011;26(7):1680-3.

Zhou B, Li H, Liu J, Xu L, Zang W, Wu S, et al. Intermittent injections of osteocalcin reverse autophagic dysfunction and endoplasmic reticulum stress resulting from diet-induced obesity in the vascular tissue via the NFøB-p65-dependent mechanism. Cell Cycle. 2013;12(12):190113 .

Ahar NH, Khaki A, Akbari G, Novin MG. The Effect of Busulfan on Body Weight, Testis Weight and MDA Enzymes in Male Rats. Intern J Women's Heal and Reprod Sc. 2014;2:316-19. 
Björndahl L, Söderlund I, Kvist U. Evaluation of the one-step eosin-nigrosin staining technique for human sperm vitality assessment. Human reproduction. 2003;18(4):813-6.

Bancroft JD, Layton C. The Hematoxylin and eosin. Theory \& Practice of histological techniques 7th ed, Churchill Livingstone of El Sevier, Philadelphia. 2013:173-214.

Oury F, Ferron M, Huizhen W, Confavreux C, Xu L, Lacombe J, et al. Osteocalcin regulates murine and human fertility through a pancreas-bone-testis axis. The Journal of clinical investigation. 2013;123(6):2421.

Oury F, Sumara G, Sumara O, Ferron M, Chang H, Smith CE, et al. Endocrine regulation of male fertility by the skeleton. Cell. 2011;144(5):796-809.

Pi M, Chen L, Huang M-Z, Zhu W, Ringhofer B, Luo J, et al. GPRC6A null mice exhibit osteopenia, feminization and metabolic syndrome. PLoS One. 2008;3(12):e3858.

Pi M, Faber P, Ekema G, Jackson PD, Ting A, Wang N, et al. Identification of a novel extracellular cation-sensing G-protein-coupled receptor. Journal of Biological Chemistry. 2005;280(48):40201-9.

Wellendorph P, Hansen KB, Balsgaard A, Greenwood JR, Egebjerg J, Bräuner-Osborne H. Deorphanization of GPRC6A: a promiscuous L- $\alpha$-amino acid receptor with preference for basic amino acids. Molecular pharmacology. 2005;67(3):589-97.

De Toni L, Di Nisio A, Speltra E, Rocca MS, Ghezzi M, Zuccarello D, et al. Polymorphism rs2274911 of GPRC6A as a novel risk factor for testis failure. The Journal of Clinical Endocrinology \& Metabolism. 2016;101(3):953-61.

Karsenty G, Oury F. Regulation of male fertility by the bone-derived hormone osteocalcin. Molecular and cellular endocrinology. 2014;382(1):521-6.

Kirmani S, Atkinson EJ, Melton LJ, Riggs BL, Amin S, Khosla S. Relationship of testosterone and osteocalcin levels during growth. Journal of Bone and Mineral Research. 2011;26(9):2212-6.

Kanazawa I, Tanaka K, Ogawa N, Yamauchi M, Yamaguchi T, Sugimoto T. Undercarboxylated osteocalcin is positively associated with free testosterone in male patients with type 2 diabetes mellitus. Osteoporosis International. 2013;24(3):1115-9.

Legrand E, Hedde C, Gallois Y, Degasne I, De Casson FB, Mathieu E, et al. Osteoporosis in men: a potential role for the sex hormone binding globulin. Bone. 2001;29(1):90-5.

Limonard EJ, Schoor N, Jongh R, Lips P, Fliers E, Bisschop PH. Osteocalcin and the pituitary-gonadal axis in older men: a population-based study. Clinical endocrinology. 2015;82(5):753-9.

El-Kamshoushi A, Hassan E, Hassaan P. Evaluation of serum level of Osteocalcin hormone in male infertility. Andrologia. 2017;49(9).

Ferron M, Lacombe J. Regulation of energy metabolism by the skeleton: osteocalcin and beyond. Archives of biochemistry and biophysics. 2014;561:137-46.

Overvad S, Bay K, Bojesen A, Gravholt C. Low INSL3 in Klinefelter syndrome is related to osteocalcin, testosterone treatment and body composition, as well as measures of the hypothalamic-pituitary-gonadal axis. Andrology. 2014;2(3):421-7. 